\title{
Perspektiewe vanuit die psigologie en sosiale wetenskappe vir kerklike bediening aan die adolossent. Deel 2: Onder- soek na die leefwêreld van die adolessent
}

\author{
J A Erasmus \& B J de Klerk \\ (Potchefstroomse Universiteit vir CHO)
}

\begin{abstract}
Perspectives from psychology and social sciences for the church's ministry to the adolescent. An investigation on the development of the adolescent

In this article meta-theoretical perspectives for youth ministry are obtained specifically from the fields of psychology and sociology. In the first place, the various psychological development phases of the adolescent are determined, as well as how they have to be accounted for in youth ministry. In the second place, the characteristics of the world in which the adolescent lives are indicated together with their influence on the adolescents.
\end{abstract}

\section{VERANTWOORDING}

Mense van dieselfde ouderdom vorm deel van dieselfde generasie. Volgens Menking (1999:154) word 'n generasie gevorm deur gebeurtenisse wat tussen die ouderdomme van 15 tot 25 jaar ' $n$ invloed op hul lewe gehad het. Dit is die ouderdom waarop jongmense hulself begin definieer vanuit ' $\mathrm{n}$ bepaalde historiese en kulturele konteks. Sekere werklikhede sal hul lewensuitkyk, verstaan en interpretasie van dit wat gebeur, vorm. Kinders wat in die laat jare sestig, die sewentigs en die vroeë tagtig gebore is, word in literatuur as deel van dieselfde generasie beskou. Hierdie generasie word algemeen Generasie X (Generation X) genoem (Codrington 1998a). Generasie X word gekenmerk deur verskeie eienskappe wat die resultaat is van vormende invloede op die lede se lewens. Omdat bepaal is dat die portuurgroep ' $n$ geweldige invloed op die adolessent het, gaan enkele vormende invloede op Generasie X bestudeer word.

- Baie van die eienskappe van Generasie X kan verstaan word deur die postmodernistiese stroming te bestudeer. Daarom gaan eers ' $n$ kort oorsig oor die postmoderne denkraamwerk gegee word.

- In die tweede plek gaan gekyk word na unieke eienskappe van Generasie $\mathrm{X}$, en faktore wat aanleiding tot dié eienskappe gegee het. 
- Daarna sal ook aandag gegee word aan enkele ander Suid(er)-Afrikaanse megatendense wat ' $n$ vormende invloed op die hedendaagse adolessent het.

\section{DIE POSTMODERNISME}

Kingma (2000:55) wys daarop dat die westerse beskawing tans 'n paradigmaverskuiwing in sy denke ervaar. Burger (1999:133) sê dat die samelewing vandag op die breekpunt tussen die moderne era en die sogenaamde postmoderne era leef. Volgens Codrington (1998b) moet die postmodernisme as ' $\mathrm{n}$ reaksiebeweging teen die modernisme gesien word. Insig in die postmodernisme kan dus verkry word deur kennis van die modernisme. Kingma (2000:55) en Codrington (1998b) identifiseer die volgende eienskappe van die modernisme:

- Daar is ' $\mathrm{n}$ beklemtoning van die individu in teenstelling met die gemeenskap;

- Die menslike verstand word die toetssteen vir die waarheid - alles moet verduidelik kan word;

- Mensgesentreerde denke is belangriker as religieuse waardes, selfs in die mate dat Skrifwaarhede bevraagteken en gekritiseer word;

- Feite is bo waardes in die wetenskap beklemtoon - absolute waarhede kan gevind en uitgeredeneer word;

- Opbloei van wetenskap en tegnologie;

- Daar is algemene sekularisasie en goddeloosheid - die mens kan alles uitredeneer en is in beheer van alles, daarom is daar nie meer plek vir God nie.

Codrington (1998b) sê dat daar drie faktore is wat aanleiding gee tot die verskuiwing van modernisme na postmodernisme: (1) geloof word afgebreek, want daar bestaan geen universele konsensus meer oor wat reg of verkeerd is nie; (2) daar is 'n geweldige toename in globalisasie geloofsisteme kom in aanraking met ander sisteme, en dit word al hoe moeiliker om enige sisteem as absolute waarheid te aanvaar; (3) daar is ' $n$ toename in polarisasie tussen verskillende kampe oor sake soos moraliteit, waarheid, opvoeding en kultuur en daar bestaan ' $n$ toenemende generasiegaping. Die volgende kenmerke van die post-modernisme kan gevolglik onderskei word:

- Daar is ' $n$ veranderende rasionaliteit. Waar die menslike rede die dominante faktor tydens die modernisme was, speel ander faktore soos menslike ervaring, gevoel, geloof en spiritualiteit nou 'n rol in die proses van ken en verstaan (Kingma 2000:56). Postmodernisme erken dat die rede ook beïnvloed word deur religieuse en ander voor- 
veronderstellings (Vorster 1996:9). Die bestaansreg van die geloof en die invloed van die geloof op die rede word aanvaar, en daardeur het die mens weer meer ontvanklik geword vir die religieuse ervaring.

- By die postmoderne mens het vaste sekerhede plek gemaak vir verskeidenheid - daar is geen absolute waarhede nie (Codrington 1998b). Dogmas en sisteme (ook godsdienstige waarhede wat ewig vas sou wees) word gewantrou. 'n Verskeidenheid van waarhede, etiese reëls en perspektiewe word erken en kan tegelykertyd geldig wees (Kingma 2000:56).

- Spiritualiteit en godsdiens is vir die postmoderne mens belangrik omdat dit erken word as die diepste essensie van menswees. Hierdie spiritualiteit beteken nie noodwendig groter gerigtheid op God nie, maar eerder ' $n$ soeke na mistieke ervarings wat verstaan word as die ware realiteit agter die gewone lewe (Kingma 2000:57). Religieuse ervaring en gevoel kom sterk op die voorgrond (Oostenbrink 1996: $60)$.

- Relativisme veroorsaak ' $\mathrm{n}$ groot verdraagsaamheid teenoor ander godsdienste. Geloof word in toenemende mate ' $n$ persoonlike saak wat elkeen volgens sy smaak inrig (Van der Walt 2001a:4). Alle godsdienste word as gelykwaardig erken. Elke mens het die reg tot eie (geloofs)oortuigings en voorveronderstelling (Oostenbrink 1996: $60)$.

- Kenmerkend van die postmodernistiese era is die groot mate van morele onsekerheid. Die vaste sekerhede van die moderniteit het plek gemaak vir verskeidenheid, vir ' $n$ pluraliteit van moontlikhede of perspektiewe (Prins 2001:106). Vorster (1996:10,19) meen dat die postmoderne mens nie vanweë sekularisasie finaal sy rug op die kerk gedraai het nie, maar dat hy nuwe verwagtinge koester van die kerk. In die postmodernisme is daar ' $n$ wêreldwye verset teen institusionalisme met sy institusionele model waar gesag afgelei word van die vorm en bestaan van die struktuur self. Daar is " $n$ soeke na gesag in ' $\mathrm{n}$ sisteem se inhoud, betekenis en funksionaliteit. Hierdie verset teen institusionalisme lei op sy beurt weer tot verset teen die tradisionele kerkmodel van die kerk as institusie met sy institusionalisme en formalisme. Die kerk kom te staan in 'n postmoderne werklikheid waarin die ou antwoorde, bedieningspatrone, institusionalisme, formalisme en tradisie-gebondenheid nie meer die eise van die dag die hoof kan bied nie.

\section{GENERASIE X (GENERATION X)}

Die naam Generation $X$ is die breinkind van die Kanadese skrywer Douglas Coupland. Hy het die term in 'n roman Life after God (1991) 
gebruik om te verwys na die jongmens van die negentigerjare. Hierdie term is deur die media oorgeneem as beskrywend van die generasie mense wat na 1965 gebore is (Menking 1999:153). Alhoewel die term sy oorsprong in Kanada en die VSA gehad het, wys Codrington (1998c) daarop dat vandag se jongmense beïnvloed word deur wêreldwye tendense. Dieselfde modes, musiek en rolprente word rondom die hele aardbol nagevolg. Van der Walt (2001b:10) sê dat die wit jeug in Suid(er)-Afrika, sterk trekke van Generasie X toon. 'n Sleutelfaktor om Generasie $X$ te verstaan, is om rekening te hou met die verskynsel van sekularisme. Volgens Menking (1999:155) is 'n gemeenskap wat gevorm is deur Christenskap vir die meeste lede van Generasie X nie eers meer ' $n$ herinnering nie. Die wêreld waarbinne geleef word, is deur en deur wêrelds en daar is vir God geen plek nie. Generasie X is " $n$ groep ontnugterde jongmense wat die idees van die postmodernisme begin toepas het op alle fasette van die lewe, en veral die godsdiens. Godsdienstige relativisme en promiskuïteit vier hoogty by hulle (Van der Walt 2001b: 10). Die ouer geslag se waardes word as irrelevant beskou omdat die leegheid daarvan ontdek is - weens die invloed van sekularisasie is daar geen basis waarop dit kan staan nie (Prins 2001:107). Allerlei skandale en wanpraktyke wat aan die lig gekom het, het die jongmens geleer om geïnstitusionaliseerde instellings te wantrou (Hunt 1997:147). Regerings met hul leuens en skandale, groot besigheidsinstansies, massa-afdankings, werkloosheid en skraal werksvooruitsigte, het hierdie wantroue in groot instellings versterk (Codrington 1998c). Daar word gevoel hierdie instellings kan nie sekuriteit belowe of lewer nie (Menking 1999:156). Hierdie wantroue geld ook die kerk as instelling (vergelyk Hunt 1997: 147). In die VSA kom die helfte van Generasie $X$ uit gebroke gesinne, ongeveer 13 van hulle pleeg daagliks selfmoord, 16 word daagliks vermoor, 1000 word daagliks ongehude moeders, 100000 bring elke dag ' $n$ vuurwapen skool toe, 2200 van hulle staak daagliks voortydig hul skoolopleiding, en 500 begin elke dag dwelms en 1000 elke dag alkohol gebruik. Hierdie generasie jongmense is pessimisties oor hul eie oorlewingskanse in die toekoms (Van der Walt 2001b:10). Generasie X beleef die wêreld nie as vriendelik nie. Dit wat hul ouers as sekuriteit gesien het (die huwelik, familie, gemeenskap en werksplek), word deur hulle wantrou (Menking 2001:156). Baie adolessente groei in onstabiele huise op waar daar nie Christelike opvoeding is nie. Daar is geen gesag, liefde of hoop op " $n$ beter toekoms nie. In baie huise is die ouers afwesig en het die sekulêre media groter inspraak as die ouer. Die gevolg is adolessente wat 'n gebrek het aan interpersoonlike vaardighede, wat huiwerig en verdedigend is teenoor ander persone en nie weet hoe om gesonde menseverhoudings te handhaaf nie. Vanweë die gebroke gesinne en samelewing waarbinne Generasie X grootword, is daar intense behoefte aan liefde en aanvaarding, en sal hulle enigiets doen om dit te kry 
(Codrington 1998c). Alhoewel hulle op die oppervlak positief en gelukkig kan lyk, is daar onder die oppervlak pyn en hartseer. Hulle beleef alleenheid, al verkeer hulle tussen baie ander mense. Hulle familie is baiekeer nie die mense met wie bloedbande gedeel word nie, maar daardie mense wat bereid is om hulle lief te hê - meermale vriende. Ware gemeenskap (oop, veilige, inklusiewe verhoudings, waar mense mekaar help) is Generasie X se hoogste waarde (Zander 1995:37-38). Ware gemeenskap kan net ervaar word in klein-groepe wat saamgebind is deur gemeenskaplike eienskappe en belangstellings. Aanvaarding in hierdie groepe is belangrik, want die groep dien as surrogaatgesin. Hiermee saam is die boodskap van die wêreld dat liefde en aanvaarding gevind word in seksuele omgang. Baie lede van Generasie $\mathrm{X}$ is dus seksueel aktief (Codrington 1998c). Tog, saam met hierdie permissiewe houding is daar vrees: vrye seksuele omgang kan lei tot selfvernietiging as gevolg van die gevaar van vigs. Hierdie vrees lei tot nog groter onsekerheid en verwarring (Zander 1995:38). Die toekoms word gevrees omdat alles onherstelbaar beskadig lyk. Jongmense voel hulle moet die skuldlas afbetaal wat die ouer geslag aangegaan het (Zander 1995:3738 ). In teenstelling met hul ouers glo hulle nie meer dat die mens die enorme probleme van hierdie lewe en die aarde sal kan oplos, of dat hulle ekonomiese situasie beter as hul ouers s'n sal wees nie. Lede van Generasie X weet dat lewe op aarde broos is, en dat die voortbestaan van die mens daarvan gaan afhang of hy ' $\mathrm{n}$ gesindheid van samewerking kan vestig, eerder as ' $n$ gesindheid van mededinging en uitbuiting (Van der Walt 2001b:10-11). Die groot helde van Generasie X is atlete, musikante, televisie- en rolprentakteurs. Mense wat tradisioneel hoog aangeslaan is (soos ouer mense, onderwysers, dokters, predikante, publieke amptenare) word nie vanselfsprekend hoog geag nie (Hunt 1997:146-147). Alhoewel die kerk as institusie gewantrou word, is daar " $n$ intense geestelike hongerte. Vanuit hulle postmoderne denkraamwerk besit hulle ' $n$ relatiwistiese godsdiensbesef. Eksklusiewe religieuse aansprake (byvoorbeeld dat net mense wat in Christus glo, gered is) is vir baie van Generasie X onaanvaarbaar (Menking 1999:157). Alle godsdienste word dikwels as ewe waar beskou en almal lei op "n manier tot " $n$ mens se saligheid. Sinkretisme is dus aan die orde van die dag (Van der Walt 2001b:11). Verdere kenmerke van Generasie $\mathrm{X}$ is volgens Codrington (1998c):

- Ware en egte verhoudings is die belangrikste van alle dinge, en omtrent enigiets sal gedoen word vir liefde en aanvaarding. Om seksueel aktief te wees is die norm;

- Individualisme word hoog aangeslaan, maar daar is " $n$ geweldige eensaamheid. Omtrent alles (veral institusionele instellings) word gewantrou; 
- Daar is pessimisme en vrees oor die toekoms. Pyn en angs word beskou as deel van die lewe. Daarom dat dwelms, drank, harde musiek en vele ander tegnieke gebruik word om tydelike pynverligting te bewerkstellig;

- Verandering is die enigste konstante, en daarom word hulle vinnig verveeld. Daar is geweldige belangstelling in tegnologiese ontwikkeling en moderne kommunikasiemiddele;

- Daar bestaan geen morele grense nie - elke mens doen wat in sy eie oë reg is. Elke mens het die reg op " $n$ eie opinie en niemand kan sê iemand anders se opinie is verkeerd nie. Die jeug voel nie gebonde aan tradisies of gebruike van vorige geslagte nie. Hulle is vry om 'n keuse te maak tussen die baie opsies wat vir hulle beskikbaar is;

- Alhoewel daar nie belangstelling in institusionele godsdiens is nie, is daar 'n ernstige spirituele soeke. Antwoorde word ook buite die Christelike godsdiens gesoek;

- Respek word verdien deur karakter en goeie menseverhoudings. Posisie en titel tel niks, persoonlikheid tel alles. Slegs iemand wat gerespekteer word, mag reëls neerlê;

- Die lewe is gejaag en baie adolessente het geweldige vol programme. Druk veroorsaak spanning en stres;

- Musiek speel ' $n$ baie belangrike rol in lede van Generasie X se lewens. Die sanger verwoord hulle innerlike gevoelens en die musiek is vir hulle 'n spreekbuis om hul lewens en emosies uit te druk.

Codrington (1998c) maak die gevolgtrekking dat Generasie X nie reëls geleer hoef te word nie. Generasie X moet geleer word om die reëls te verstaan, en dan die ruimte gegee word om die reëls vir hulself toe te pas.

\section{ANDER MEGATENDENSE WAT 'N INVLOED OP DIE ADO- LESSENT SE LEEFWÊRELD HET}

Soos reeds hierbo gesien, het verskeie tendense in die samelewing ' $n$ invloed op die vorming van die adolessent (vergelyk Louw 1992:432433). Kennis van hierdie tendense is dus noodsaaklik. In hierdie onderafdeling word kortliks gekyk na enkele megatendense van die SuiderAfrikaanse samelewing wat ' $n$ invloed op die ontwikkeling van die adolessent kan hê. Volgens die verklaring van die Konvent van Reformatoriese Kerke in Suider-Afrika (1999:8-9) kan die volgende tendense in die Suid-Afrikaanse samelewing onderskei word:

- Geweld en misdaad is aan die orde van die dag;

- Armoede neem geweldige afmetings aan; 
- Aborsie is gewettig en word op aanvraag gedoen;

- ' $\mathrm{n}$ Gesonde werksetiek word bepleit - hieruit kan afgelei word dat daar " $n$ ongesonde werksetiek onder " $n$ groot deel van die SuiderAfrikaanse samelewing is;

- Daar is ' $n$ agteruitgang in mediese dienste in hospitale. Sedeloosheid en losbandigheid dra grootliks hiertoe by. Die verklaring van die National Consultation of Churches in South Africa (1999:9-10) wat van 22 tot 26 Februarie 1999 te Rustenburg gehou is, het die volgende tendense in die Suider-Afrikaanse samelewing uitgelig:

- Bevoorregte sowel as agtergeblewe gemeenskappe kan in SuiderAfrika onderskei word;

- Armoede teister baie gemeenskappe in Suider-Afrika en dit gee aanleiding tot moedeloosheid;

- Misdaad en geweldsmisdaad vernietig die moraal in die land en vererger die omstandighede van armes. Die regstelsel is nie in staat om behoorlik te funksioneer nie en dit vererger die misdaadprobleem;

- Algemene losbandigheid en sedeloosheid gee aanleiding tot baie buite-egtelike geboortes en die vinnige verspreiding van HIV/Vigs;

- Opvoeding in skole beleef ' $\mathrm{n}$ groot krisis. Ook Potgieter (2000:46, 53-54) stel dat landsburgers in Suid-Afrika gekonfronteer word deur armoede, misdaad en eindelose politieke en sosiale verdeeldhede ten opsigte van etnisiteit, klas, ras, taal en godsdiens. Die groep burgers wat voorheen bevoorregtes was, beleef meestal dat die hele samelewing in duie stort en dat standaarde val. Hulle kan maklik vervreem raak van die samelewing omdat hulle gevoelens van kwesbaarheid, gebrek aan beheer oor die lewe en 'n gesensitiseerdheid kan hê vir alles wat moontlik kan skeefloop en gebeur. Van der Walt (1999:38, 42) sê dat die ingrypende strukturele veranderinge wat die afgelope paar jaar in die Suid-Afrikaanse samelewing plaasgevind het, wydverspreide onsekerheid, diskontinuïteit en diversiteit tot gevolg gehad het. Hierdie nuwe tydsgees bring ' $n$ afsluiting van die wêreld mee, ' $n$ na binne gerigte godsdiens, negativisme, 'n soeke na relevansie en geloofwaardigheid, maar ook protes en eksperimentering met die nuwe. Baie mense is afsydig en negatief, maar daar is ook mense wat besonder positief dink. Die meeste mense is egter positief oor sommige en negatief oor ander ontwikkelinge. In ' $n$ ondersoek gedurende Mei 1999 in die Nederduits Gereformeerde Kerk, is die volgende verskillende groeperings onderskei: (1) conformists $(19,6 \%)$, (2) traditionals $(20,5 \%)$, (3) progressives $(18,8 \%)$, (4) non-conformists $(17,0 \%)$, en (5) die todayers $(24,1 \%)$. Die conformists huldig tradisionele waardes, is sterk op die groep gerig en gooi wal teen veran- 
derings. Die traditionals en progressives wil, met behoud van sekere ononderhandelbare beginsels, by die veranderings aanpas en vernuwe. Hulle waardes lê klem op persoonlike ontwikkeling en vooruitgang. Die non-conformists en todayers is soepel en pragmaties ingestel en wil met die nuwe eksperimenteer. Hulle verwerp tradisie en groepsgebondenheid, lê klem op die kleingroep en die individu en is selfs hedonisties georiënteerd (Van der Walt 1999:45). Potgieter (2000:54) wys daarop dat dit moontlik is om die eienskappe van ' $\mathrm{n}$ getraumatiseerde gemeenskap binne die tradisionele Afrikaanse samelewing te identifiseer. Vertroue is verloor in die tradisionele leierskorps, daar is ' $n$ ongeërgdheid in kerklike instellings en ' $n$ verlies aan basiese vertroue onderling (en selfs in God). Kortweg: lidmate soek rigting in hulle lewens.

\section{META-TEORETIESE PERSPEKTIEWE VANUIT DIE LEEF- WÊRELD VAN DIE ADOLESSENT}

Uit die ondersoek na die leefwêreld van die adolessent het dit duidelik geword dat die gemiddelde adolessent ' $n$ kind van sy tyd is, en beïnvloed word deur die algemene denkstroom in die samelewing. Die jeug (Generasie X) word sterk gevorm deur die postmoderne beweging. Die afbreek van grense maak dat die jeug wêreldwyd deur dieselfde tendense geraak en beïnvloed word. Vanuit die postmodernisme kan die volgende metateoretiese perspektiewe afgelei word:

a) Die kerk moenie historiese vorme van die kerk probeer bemark nie, maar die Bybelse etiese beginsels oortuigend aan die postmoderne jongmens oordra. Bybelse waarhede moet so ingeklee word dat die postmoderne jongmens met sy unieke spirituele instelling dit in sy lewensbeskouing en beoefening van spiritualiteit kan integreer (Vorster 1996:18).

b) Teenoor institusionalisme en formalisme is daar ' $\mathrm{n}$ behoefte aan kontekstualiteit en funksionaliteit in kerklike bediening. Die vraag word gevra: het die kerk waarde vir die mens? Kerklike bediening moet die mens se behoefte aan religieuse ervaring, betekenis en gemeenskap met ander aanspreek (Vorster 1996:19).

c) Sekularisasie oefen geweldige druk uit op die uitleef van 'n Christelike lewens- en wêreldbeskouing. Daar moet begrip wees vir hierdie druk waaronder die jeug verkeer sodat strategieë uitgewerk kan word as teenvoeter vir sekularisasie.

d) Die hernude klem op spiritualiteit in die postmoderne samelewing stel die kerk voor die uitdaging om ware Christelike spiritualiteit te beklemtoon en uit te bou in die lewe van lidmate (Kingma 2000:57). 
Christelike spiritualiteit moet beklemtoon word omdat baie mense antwoorde ook buite die Christelike godsdiens soek.

e) Omdat die adolessent die wêreld as onvriendelik beskou, moet die kerk met ware Christelike liefde na hom uitreik. Die stabiliteit wat hy in die kerk vind, moet die onstabiliteit teenwerk wat hy in die gesin en samelewing ervaar. Die kerk moet bewustelik daartoe werk om stabiliteit in verbondsgesinne te kweek.

f) Omdat ' $n$ verskeidenheid waarhede, etiese reëls en perspektiewe erken word, moet die adolessent die noodsaak van die Christelike etiek op so " $n$ wyse geleer word dat hy die onmisbaarheid daarvan vir sy eie lewe insien. Hiermee sal die probleem van morele onsekerheid ondervang word.

g) Adolessente sal slegs luister na ' $n$ verkondiger wat gerespekteer word. Aanspraak op posisie, titel of persoonlikheid tel nie. Respek word verdien deur karakter en goeie menseverhoudings. Verkondiging deur dade tel dus vir " $n$ adolessent meer as verkondiging deur woorde.

h) Die eienskappe en optrede van Generasie $X$ is baie keer ' $n$ reaksie op emosionele verwaarlosing en ' $\mathrm{n}$ kreet om aandag en erkenning (vergelyk Prins 2001:107). Die kerk moet hierdie smeekroep beantwoord.

i) Daar moet empatie en geduld wees met die feit dat baie adolessente oor gebrekkige interpersoonlike kommunikasievaardighede beskik. Toerusting tot die aankweek van gesonde menseverhoudings moet verskaf word.

j) Vanweë die waarde wat die adolessent aan die portuurgroep heg, kan aandag gegee word aan die ontwikkeling van Christelike kleingroepe waar adolessente met gemeenskaplike eienskappe en belangstellings saamgebind kan word.

k) In 'n tyd van vrees, pessimisme en moedeloosheid moet die Christelike hoop weer sterk aan die jongmens verkondig word. Die adolessent moet getroos word met die boodskap dat God in beheer bly ten spyte van die gebrokenheid van die wêreld.

1) Spanning en stres kan verlig word deur gereeld ontladings- en ontspanningsaktiwiteite te beoefen.

m) Omdat enige inligting met die druk van ' $n$ knoppie gevind kan word, moet opvoeders nie papegaaiwerk vir adolessente gee nie. Jongmense moet geleer word waar om inligting te kry, wat om daarmee te doen, hoe om die inligting te verwerk, en hoe om afleidings uit die inligting te maak (Van der Walt 2001a:7). 
n) Adolessente raak vinnig verveeld. Nuwe kreatiewe beplanning is voortdurend nodig om die aandag van die jongmens te behou. Dieselfde program moet dus nie week vir week en jaar vir jaar gevolg word nie.

o) Omdat adolessente in ' $\mathrm{n}$ gejaagde lewe met vol programme grootword, moet elke geleentheid waar met die jeug gewerk word, optimaal benut word. Indien die adolessent voel dat hy sy tyd mors, sal hy nie weer opdaag nie.

p) Die adolessent heg baie waarde aan musiek omdat hy voel dat sy innerlike emosies daardeur verwoord word. Aandag moet gegee word aan die plek van musiek in die lewe van die jongmens. Vanuit die Suid(er)-Afrikaanse samelewingstoestande kan die volgende metateoretiese perspektiewe verkry word vir jeugwerk:

q) Geweld en misdaad skep baie onveiligheid en onsekerheid. Die kerk en ouerhuis moet ' $n$ veilige en sekere hawe in die onstuimigheid wees.

r) Algemene losbandigheid, sedeloosheid en die wettiging van aborsie skep die indruk dat vrye seksuele verkeer toelaatbaar is. Sterk klem moet op Christelike waardes, en die motivering daartoe, gelê word.

s) ' $n$ Ongesonde werksetiek is ' $n$ kenmerk van die Suid(er)-Afrikaanse samelewing. Verkondiging, onderrig en getuienis aangaande ' $\mathrm{n}$ Bybelse werksetiek is dringend noodsaaklik.

t) Deur die jeug aktief by liefdesdiens en hulpbetoning aan armes en minderbevoorregtes te betrek, kan praktiese onderrig en dienswerk in diakonia verskaf word. Baie lidmate raak vervreem van die samelewing omdat hulle hulle terugtrek weens politieke en sosiale redes. Jong lidmate moet daarop gewys word dat hulle hul roeping net kan uitleef deur na buite uit te reik.

u) Daar moet sensitiwiteit wees vir die feit dat jongmense verskillende sienings huldig wat betref landsake. Die jeug in die gemeente is nie ' $n$ homogene groep nie.

v) Omdat dit blyk dat die tradisionele Afrikaanse samelewing op hierdie stadium die eienskappe van 'n getraumatiseerde gemeenskap toon, moet die kerk sterk leiding aan die lidmate gee, veral aan die jonger lidmate.

w) Omdat die opvoeding in die skole in "n krisis is, sal kerke ernstig moet waak en toesig hou oor die opvoeding wat die skoolgaande jongmense ontvang. 


\section{SAMEVATTING VAN META-TEORETIESE PERSPEKTIE- WE OP DIE ADOLESSENT}

Die volgende meta-teoretiese perspektiewe is verkry:

a) Gedurende adolessensie ondergaan die jongmens verskeie stadia van ontwikkeling. Ontwikkelingstipes wat onderskei word, is biologiese veranderings, kognitiewe veranderings, morele ontwikkeling, emosionele ontwikkeling en sosiale ontwikkeling. Alhoewel die verskillende ontwikkelingstipes onderskei kan word, is hulle tog nou met mekaar verweef.

b) Die kognitiewe ontwikkeling wat die adolessent ondergaan, stel hom/ haar in staat om groter intellektuele take te verrig. Abstrakte denke vind plaas, daar kan langer gekonsentreer word, norme en waardes kan geleer en verstaan word, en die adolessent kan selfstandig funksioneer.

c) Die portuurgroep speel ' $\mathrm{n}$ geweldige rol. Alhoewel die portuurgroep negatief gesien kan word, kan dit ook positief gesien word. 'n Christelike portuurgroep kan Christelike waardes help vestig en aanmoedig. Ten spyte van die portuurgroep het die ouers egter nog 'n geweldige impak op die sosiale vorming van die adolessent. Ook ander volwassenes in die kerk kan as rolmodelle vir die jeug optree.

d) Die adolessent van vandag word sterk gevorm deur postmodernistiese neigings. Die jeug in ' $n$ spesifieke geografiese gebied leef nie afgesluit van die res van die wêreld nie. Daar is ' $n$ redelik eenvormige wêreld jeugkultuur (Generasie X). Die wêreld waarbinne hierdie jongmense leef, is uiters sekulêr en ' $\mathrm{n}$ verskeidenheid waarhede, etiese reëls en perspektiewe (nie noodwendig Christelik nie) word erken.

e) Die adolessent se kritiese vrae oor ander gelowe, geloofsbelewing en die kerk moet gesien word as vordering langs die weg om ' $n$ eie verantwoordelikheid vir eie geloofstandpunte te aanvaar. Liefdevolle, geduldige en Skriftuurlike begeleiding is hierin van groot belang (vgl Kingma 2000:67). Egte en betroubare pastorale betrokkenheid by die adolessent is noodsaaklik, veral in die lig van die waarde wat aan interpersoonlike verhoudings geheg word.

f) Toerusting moet gegee word om die adolessent se roeping uit te leef in 'n wêreld waar geweld en misdaad, armoede, siekte en werkloosheid hoogty vier. Die geleentheid moet ook geskep word om hierdie roeping uit te leef.

g) Daar is weerstand teen die kerk as institusie. Deur aandag te gee aan die kerk as organisme en die roeping van die kerk in die wêreld, kan hierdie weerstand afgebreek word. Die bediening van die kerk as 
institusie is ondergeskik aan en moet in diens staan van die kerk as organisme se roeping in die wêreld. Sondag is op Maandag tot Vrydag gerig. Sondag se kerkdiens is op Maandag se lewensdiens gerig (Van der Walt 1999:14).

\section{Literatuurverwysings}

Burger, C 1999. Gemeentes in die kragveld van die Heilige Gees. Oor die unieke identiteit, taak en bediening van die kerk van Christus. Stellenbosch: BUVTON.

Codrington, G 1998a. Generation X: Who, what, why and where to? Chapter 1: Generational Theory - the history of our future. [Internet:] http://www.youth.co. za/genxthesis/ch1.htm. [Datum van gebruik: Aug. 18, 2001].

-, 1998b. Generation X: Who, what, why and where to? Chapter 2: Postmodernism - the Future's not what it used to be. [Internet:] http://www.youth.co.za/genxthesis/ ch2.htm. [Datum van gebruik: Aug. 18, 2001].

-, 1998c. Generation X: Who, what, why and where to? Chapter 3: Defining Characteristics of Generation X. [Internet:] http://www.youth.co.za/genxthesis/ch3.htm. [Datum van gebruik: Aug. 18, 2001].

Coupland, D 1991. Life after God. New York: Simon \& Schuster.

Hunt, D G 1997. Holding on to the gospel and each other. American Baptist Quarterly 16(2), 145-153.

Kingma, B R 2000. Die pastorale begeleiding van universiteitstudente in hulle dienswerk as Christene. Ongepubliseerde Th.M.-verhandeling, PU vir CHO.

Konvent van Reformatoriese Kerke in Suider-Afrika. 1999. Verklaring van die Konvent van Reformatoriese Kerke in Suider-Afrika. Woord en Daad 367, 8-9.

Louw, D A 1992. Menslike ontwikkeling. (Tweede uitgawe). Pretoria: HAUM - Tersiêr.

Menking, S J 1999. Generation X: the first post-christendom generation. Quarterly Review 19(2), 153-166.

National Consultation of Churches in South Africa. 1999. Declaration. Woord en Daad $367,9-10$.

Oostenbrink, J W 1996. Korporatiewe spiritualiteit en kleingroepleierskap. Ongepubliseerde Th.D.-proefskrif: Potchefstroom. PU vir CHO.

Potgieter, M C 2000. Die sosiaal-psigologiese impak van die transformasieproses in Suid-Afrika op lidmate van die Ned Geref Kerk. Acta Theologica 2000, Supplementum 1, 45-57.

Prins, J M G 2001. Intensionele morele vorming: noodsaaklik in kerklike jeugbediening. Praktiese Teologie in Suid-Afrika, 16(1), 105-119.

Van der Walt, B J 1999. Kerkvernuwing onderweg na 2000. Visie - missie - konteks. Potchefstroom: PU vir CHO (Instituut vir Reformatoriese Studie).

Van der Walt, J L 2001a. Education to survive in a tough new world. Woord en Daad $375,2-8$.

-, 2001b. Toestande wat ons kerklike voortbestaan beïnvloed - 3. Die Kerkblad, 104 (3113), 10-12, Aug. 1. 
Vorster, J M 1996. Is die kerk funksioneel? Gedagtes oor gereformeerde kerkvernuwing in ' $n$ postmoderne konteks. Potchefstroom: Potchefstroomse Teologiese Publikasies.

Zander, D 1995. The gospel for Generation X. Making room in the church for "busters". Leadership, 16(2), 36-51. 